\title{
Studies on Chinese-English Brand Name Translation from the Perspective of Cross-cultural Communication
}

\author{
Lu Wenchan \\ School of Journalism and Communication, Central China Normal University, Wuhan 430079, China \\ luwenchan@qq.com
}

Keywords: Brand name; Cultural differences; Translation methods

\begin{abstract}
In the age of economic globalization, the communications between human beings are more frequent, and the trends of Chinese-western trade have increased greatly. In the process of international trade transactions, the brand name takes an immeasurable, as well as an irreplaceable part. Brand name, the image representative of the product and the company, is the direct element to attract the customers' attention and evoke their desire to buy the products, which is the key to the sales volume. However, for the different social ideology, customs and habits, aesthetic psychology, and value, the translation processes are often hindered. From the perspective of cross-cultural communication, this paper aims at analyzing the specific cultural differences of the brand name, finding out the factors causing the differences and giving a series of proper solutions to deal with these thorny problems. What's more, this paper has collected quite a number of Chinese-English brand names, aims at comparing the source language brand name and the target language brand name, and has found out some deficiencies, like direct translations without considering the cultural factors. For these problems, this paper puts forward several translation principles and methods under the guidance of Eugene A. Nida's functional equivalence theory from the cultural viewpoint in order to give a reference to the Chinese-English brand name translation.
\end{abstract}

\section{Introduction}

As the world trade booming and China's initiative of "Belt and Road", China has taken an important and conspicuous role in the foreign trade business which is an inseparable part to improve our comprehensive national power. In order to be more competitive in the foreign trade, we should be more powerful in the foreign market which is the fundamental to disseminate products and make great profits. Therefore, it is inevitable to refer to the brand names.

When it refers to the international market, it is inevitable to attach importance to the translation of the brand name for its products. A brand name is the most direct and striking element to show its products and to expand its oversea market.

A good brand name translation is easier to attract the customers' attention, while a bad brand name translation may resist the customers to learn the products. Then, in order to take a certain role in the foreign market, we should pay more attention to the brand name translation in order to expand our foreign trade business.

\subsection{Definition of culture}

Culture is a very complex and abstract system, which encompasses a broad area. Different research field has a distinct concept. It seems invisible, but it immerses into many aspects of our daily life. Sometimes, our behavior, communication mode, and thinking-patterns are shaped by culture unconsciously. In the beginning, "culture” originates from the Latin word "cultura”, which is correlated to the meaning of "cultivating”. It has many definitions. Edward B. Tyler (1871:213) points out in The Primitive Culture, "culture or civilization includes knowledge, faith, arts, moral, law, customs and ability that people get as a member of the society from the extensive ethnological significance.”

Neuliep (2006:21) defines culture as "an accumulated pattern of values, beliefs, and behaviors, shared by an identifiable group of people with a common history and verbal and nonverbal 
systems.”

Eugene A. Nida (2002:108) refers culture to these aspects: social culture, material culture, ecological culture, religious culture, and linguistic culture.

A Chinese scholar, Qi Yucun(1992:2) makes a thorough summary, who gives a definition from the broad and narrow aspects, he notes, "the broad culture is the summation of the material and mental wealth in the process of the human development, and the narrow culture means the social ideology, sometimes specifically points to education, science, literature, and arts.”

The definition of culture varies from the different researchers. It involves an extensive scope of our life which is deserved to be researched deeply to get a better understanding and direction to our life.

\subsection{Definition of brand name}

In the fierce international business environment, every company is making strenuous effort to make their products to be stood out fast among the multiple and competitive ones. The first significant way to get that effect is to design an acceptable and remarkable brand name.

Bhimrao M. Ghodeswar(2008:4-12) remarks, "Branding is a set of marketing and communication methods that help to distinguish a company or products from competitors, aimed at creating a lasting impression in the minds of customers. The key components that form a brand's tool box include a brand's identity, brand communication, brand awareness, brand loyalty, and various branding strategies."

The contemporary Chinese dictionary defines the brand name as “ it is the mark, sign(words like drawing and patterning ) which are printed on the cover of the product or the packaging ”, which is similar to the Kotler's. Kotler(1991) refers to it as"the name , term, signs, symbol, design, or a combination of these elements to identify the goods or services from one product or group of products and to differentiate them from those competitors".

The brand name is an invisible wealth to the product and the corporation. Usually, the good brand name involves following feature: unique, legible, valuable, memorable, connotative.

\subsection{Cultural differences and brand name translation}

Language makes great contributions to the development of society. From ancient to present, people huddling together possess the same language system. They learn, work and develop in the same cultural background. But it is the language that separates the communication of people who live in a different place with the different cultural background. Language is a part of culture and also the carrier of culture. The relationship between language and culture determines that the translation process is not only to transfer language, but also the implication of culture. Culture is unique, which is developed under the long developmental history. Even-Zohar(1990:5) remarks"translation is not inflexible once the nature and boundary being ensured, but an activity that depends on an multiple relationship in a specific cultural system ."this definition indicates that the translation is not just limited to words, phrases, but also the cultural implication. It is necessary for a translator to grasp the different culture information in the translation process.

Culture plays an important role in the brand name translation. Now the translation is a very complex and also difficult process. Owing to the different cultural background, people have different thinking-patterns, customs and habits, religious beliefs, therefore it is really urgent that the translators should take a good command of both cultures. The successful brand name can not only catch the attention of the customer, and exert a great impact on the international business trade, but also to disseminate diverse cultures to some extent.

\section{Cultural Factors Causing the Differences in Chinese-English Brand Name Translation}

Usually, the gaps and clashes often occur in the translation process, including the language, semantics and culture implications. The following will mainly discuss the factors which cause the cultural difference in the process of brand name translation. 


\subsection{Different customs and habits}

Usually, we confine customs and habits as ideology and behavior, which is accustomed by the people for a long time. The customs and habits are intrinsic components of culture. It comes into being with the unique developing history of the countries. We are shaped by the customs and habits unconsciously.

In China, we often use the color"hong”(red) to express fortune, happiness. We often use“Hongxi” to celebrate the birthday, wedding or admission into the university. And some phrases include "hong"showing their best wishes, or compliment, such as"honghong huohuo", "chazi yanhong", "hongguang manmian”. There are also some words shaped in the brand name. such as: the brand names"Hongxing”(Red Star), "Hongqi”(Red Flag), "Hongcha”(Black Tea), While, in the English-speaking countries, "red" is the symbol of blood and violence.

The cultural differences of customs and habits have also reflections on the foods and clothes. We can call it as material cultural. The traditional Chinese clothes, “qipao”, "Zhongshan zhuang”, “Tang zhuang"are popular clothes with Chinese cultural features. While in western countries, the popular clothes are "jeans”, "suit”, “jacket”. The Chinese characteristic food“jiaozi”, "tangyuan”, "zongzi” are absent in the English-speaking countries while "salad", "hamburger", and "milk" are their unique daily food in the West.

\subsection{Different aesthetic psychology}

People live in the certain cultural environment. It is inevitable that his thinking-patterns, behaviors and aesthetic sense are bestowed with unique cultural characteristics. Taking the "Hehua"(Lotus) for example, in China, the Lotus is the symbol of a decent gentleman or a graceful lady, and appearing frequently in construction, sculpture, literature, and drawing. The Chinese poet once praised Lotus for its purity and loyalty. It stands for love and elegance. We often regard it as the best wishes to the lovers, While in the western countries, it is mere a kind of plant. There is also another example to indicate the different aesthetic ideology: the brand name"Puma"is translated as"Biaoma" when it is introduced into China. As a matter of fact, the original meaning of the word is "Jaguar", in order to avoid the association of atrocious beast to the Chinese people, and make people associate it with the intrepid image, then there comes"Biaoma"(Splendid horse), which conveys the spirits of the brand name. In China, we often correlate the brand name with the word"Na”, "Fang”, "Shi”, "Lei”, "Ya”to show the sense of beauty. Such as :"Lulanjina”, "Yafang”, "Yibeishi", "Shulei", "Yayang". Likewise, in English-speaking countries, the sun is deemed as Jesus. Many brand names are equipped with "sun”. such as, "Sunwood”, "Sunjoy”, "Sunenergy”, and"Suntour".

\subsection{Different value system}

Values have a broad realm of dominence. It is a rule of your daily life. Kluckhohn(Hu Wenzhong, 1999) thinks, "values is explicit or implicit concept of individual or collective, which guide our behavior, choice ". Samovar and Porter (2001) remarks, "values are always rules, which tell people what is right and wrong, what is true and false". In other words, values are the concrete or abstract objects to decide our behavior and thinking-patterns. It indicates that the brand name translation is influenced at a large extent for the different values of China and English-speaking countries.

In China, people are more inclined to collective. We often call for the harmony of the group, the mutual goals, and the collective strength. Although we carried out the private ownership in the ancient, we still stressed the importance of harmony between people and society. The relationship, “jun chen”, "chen chen”, "wanghou jiangxiang” also reflect the collective thinking. Today, we can often hear the expression to show the collectivism. Such as "Jiemei tao", "Tuanjie". It is also expressed in the brand name. Such as "Haodangjia", "Dazhong". While in the western countries, people pay more attention to individual feelings. They highly value individualism. When the clashes happen among them, they strive for themselves under the guidance of the values of individualism. "American Dream" is the representative example to show the sense of individualism. Some brand names also reflect the concepts. Such as"Boss”, "King Coke”,"True Luxe”. 


\section{The Methods of Brand Name Translation}

The process of brand name translation is not only to convey the semantic and cultural meaning, but also to show the function of the product. As Nida says, “the closet natural equivalent”. In order to reach the purpose, it is recommended to use the following methods properly to cater to a specific situation.

\subsection{Transliteration}

Transliteration is a translation method that transcribes the same or similar pronunciation between the original and target language to translate the name of the product. The translators pay more attention to the sound and function of the product.

Taking some products for example,“Benz”, a famous car, is translated into "Benchi”, both of which are similar in the pronunciation and give customers the impression that the car can run very fast. The brand name of shoes "reebok" is translated into"Ruibu". Through the vivid translation, the Chinese can get the meaning and function quickly. The primary purpose in the translation process is make full understanding of the function and meaning of the source-language text.(Nida.1993) These brand names convey the theory exactly and successfully. There are also some brand names which only conveys the pronunciation and do not have any meaning or function. Such as ,"Kodak"(Keda), “Dior”(Aodi), “Intel”(Yingteer) .

\subsection{Literal translation}

The literal translation means that using the corresponding target words directly according to the original brand name meaning. When we use the literal translation, it is usually the brand name which has a precise meaning, good cultural implication and the function is equivalent. As Nida remarks(2002),"if a more or less literal correspondence is functionally equivalent in both designative and associative meaning, then obviously no adjustments in form are necessary." It indicates that we should pay more attention to the meaning and function instead of the form.

For example, the foreign cigarette"Dynasty"is translated into "Huangchao". In Chinese, "Huangchao"means power and wealth. It gives the customers an illusion that if they smoke the cigarette "Huangchao", their status and taste will improve accordingly. It stimulates the customers to buy the product inadvertently. The car brand name"Bluebird"is translated into "Lanniao" (Bluebird). The brand name "Bluebird"originates from the pantomime"Bluebird"which is created by the Belgian author. In the pantomime, the "Bluebird" is the symbol of "the future happiness". In China, it represents the object which can be the bailment of our "lovesickness".

In the above examples, they have the same referential meaning and cultural implication in the target language and source language which can associate the customers with the same feelings of China and western countries. However, there are also some circumstances that we cannot use the literal translation accounting of the different cultural message. Such as, "Bianfu"(bat) , "Baixiang”(white elephant), "Jinji”(Golden Cock) all are failure translation because of the different cultural implication. Therefore, it is important for us to pay more attention to the connotation and association of the brand name in the process of translation to avoid the cultural clashes.

\subsection{Free translation}

When both sounds and meaning can't show the value of the product, it is a best choice to use the free translation. The free translation is also called "paraphrasing translation". It means combines the similar pronunciation and related meaning in the target language to translate the original brand name.

In general, the meaning of the brand name is combined with denotative meaning and connotative meaning. However, owing to the different cultural system, some words have the same referential meaning with different associative meaning, sometimes; even the referential meaning is different. For example, "Fangfang", at first, we adopted the transliteration. It was translated into"Fangfang". Although the pronounciation and form were the same, we overlooked that "fangfang" is a kind of animal with sharp teeth in the western countries. It is too terrible to buy the product for the 
customers. Later, we use the literal translation and translate it into"Fragrance", it has the similar sound and association. "fragrance"gives the foreign customers an impression of beautiful, balmy and sweet feelings. Another example, the soap"safeguard"is translated into "Shufujia"(comfortable and good skin). In China, it is popular among customers. The beauty of rhyme, and the multiple functions evoke the customers comfortable, relax and safe feelings, which motivates the customers to buy it.

\subsection{Derivative translation}

The brand name is an important way to disseminate your product. It can be regarded as a commodity culture. It is necessary to follow the social habits and aesthetic psychology. Nida(2002:10) once remarked,“ biculturalism is more important compared with the bilingualism, since words only have meanings in the cultural backgrounds in which they function”. Therefore, it is important to take cautious attitudes in the process of brand name translation for the translator. The derivative translation methods are usually employed when there is cultural clashes, or to reach the cultural equivalence.

For example, the famous militarist Cao Cao, wrote in The Short Song Ballad,"He yi jieyou,wei you Dukang”. Then, "Dukang"is widely used in China to represent "wine”. For the famous poem, the brand name"Dukang" is widely popular in China. In the western countries, Bacchus and Dionysus are called as the "embodiment of wine", it is suitable to translate the brand name "Dukang" into "Bacchus"or "Dionysus". Both convey the same cultural implication. Sometimes, it is the cultural clashes that we have to adopt the derivative translation. For example, the brand name“sprite". In the western countries, associative meaning of "sprite" is "naughty", "childish". If adopting the literal translation, it means "Yaojing"(evil spirit), or"Mogui"(demon) in China. The Chinese hate and are scared of it. At last, it's translated into "Xuebi" (snowy blue) which is popular in China and sells well. The "Xuebi”leaves the customers an impression of being pleasant and cool. This derivative brand name translation is highly accepted and appreciated by the translators.

In the severe international business trade, the quality of the product is very important, nevertheless the brand name is also the key point to motivate the customers to buy the product. The brand name is the first object that the customers start to learn the product. It is the image representative of the product and the company. We have mentioned four translation methods. In the specific Chinese-English brand name translation, we should take the language, semantic and cultural meanings into consideration, then to adopt the best translation method.

\section{Conclusion}

With the construction of the world community with a shared future , the trends of international business trades are more frequent. It is necessary and urgent to broaden the research fields and make great efforts on it. The translators should realize the importance of the mission. This paper has adopted many examples to get the customers learning the charm of the products and motivate the translators to study the brand name under the influence of different cultural background. It is the different cultural system that the research process is rather hard and complex for the translators. But it doesn't mean that the obstacles of brand name translation are impossible to solve. In this paper, the author takes several strategies and put forward several translation principles to analyze the brand names under the guidance of Eugene A. Nida's functional equivalence theory. We should always follow the rules that the informative function and cultural implication are more important factors compared with the lexical and formal impacts that we should not overlook in the translation process.

Although the author has put forward the translation principles and strategies of the brand name under the influence of cultural difference. There are still some regrets and limitations in this paper. Firstly, accounting of the author's limited knowledge, it is difficult to make a deep analysis about the brand name translation from the broad cultural perspectives. Secondly, most of the above products are quite obvious examples, and there are some difficult brand names are shunned to be analyzed. Thirdly, Nida once remarked (2002), "the maxim of equivalence is an ideal expectation, 
which is really difficult to realize accounting of the cross-cultural communication. And some loss and distortion are inevitable since no two interlocutors have the same designative and associative meaning for the different lexical, grammatical, phonological, and discourse features". It indicates that we should seek the closet natural equivalence, but it not always can be achieved. In a word, the brand name translation is a complex and difficult process. It is not only to converse the language, but also the culture. The translators should be prudent to avoid the false brand translation due to the cultural differences. In addition, culture is not stagnant. The translators should pay attention to its changes to make better preparations for the brand name translation.

\section{References}

[1] Bhimrao, M. Ghodeswar. Building Brand Identity in Competitive Markets: A Conceptual Model [J]. Product \& Brand Management, 2008.

[2] Bonvillain, Nancy. Language, Culture and Communication: The Meaning of Message [D]. America: Pearson Prentice Hall, 1993.

[3] Even-Zohar, Itmar. Polysystem Studies [J]. Poetics Today, 1990.James W. Neuliep . Intercultural Communication: A Contextual Approach.[M] London: Sage Publications. 2006(3).

[4] Kotler, P. H. Marketing Management: Analysis, Planning, Implementation, and Control [M]. Englewood Cliffs, NJ: Prentice Hall. 1991(7).

[5] Larry A Samovar\& Richard E.Porter.Communication Between Cultures[M].Beijing:Foreign Language Teaching and Research Press.2000(3).

[6] Nida, Eugene A. \& de Waar. Toward a Science of Translating With Special Reference to Principles and Procedures Involved in Bible Translating [M], Leiden: E.J, Brrill, 1986.

[7] Nida, Eugene A., Language, Culture, and Translating [M], Shanghai: Shanghai Foreign Language Education Press, 2002.

[8] Nida, Eugene A. \& Charles, RT., the Theory and Practice of Translation [M], The Netherlands: E.J.Brill, Leiden, 1982

[9] Nida, Eugene A. Language and Culture: Context in Translating [M]. Shanghai: Shanghai Foreign Language Education Press. 2001.

[10] Tylor Burnett Edward. Primitive Culture [M]. London: John Mary, 1871.

[11] Jun, Xu. An Exploration of the Cultural and Social Outlook in the Practice of Translation[J] Chinese Translators Journal, 2004(1):51-55 